\title{
CARACTERÍSTICAS MORFOFISIOLÓGICAS DE ABACAXIZEIRO 'GOMO DE MEL' ENRAIZADO IN VITRO SOB LUZ NATURAL E SUBSTRATO VERMICULITA ${ }^{1}$
}

\author{
FRANCYANE TAVARES BRAGA ${ }^{2}$, MOACIR PASQUAL ${ }^{3}$, \\ EVARISTO MAURO DE CASTRO ${ }^{4}$, GABRIEL COIMBRA RAFAEL ${ }^{5}$
}

RESUMO - Objetivou-se avaliar o efeito da vermiculita, ágar, da luz artificial e a da natural no enraizamento in vitro de brotos de abacaxizeiro 'Gomo de Mel', bem como caracterizar anatomicamente essas plantas. O trabalho foi realizado no laboratório de Cultura de Tecidos Vegetais, do Departamento de Agricultura UFLA, Lavras-MG. Foram utilizados brotos com $2 \mathrm{~cm}$ de comprimento, cultivados em meio MS acrescido de 30g. $\mathrm{L}^{-1}$ de sacarose. Testaram-se dois suportes físicos: $6 \mathrm{~g} . \mathrm{L}^{-1}$ de ágar e $15 \mathrm{~g} . \mathrm{L}^{-1}$ de vermiculita para o enraizamento dos brotos em dois ambientes: sala de crescimento a $25 \pm 1{ }^{\circ} \mathrm{C}, 45 \mathrm{~W} \cdot \mathrm{m}^{-2} \cdot \mathrm{s}^{-1}$ durante 16 horas e casa de vegetação com radiação de $115,08 \mathrm{~W} \cdot \mathrm{m}^{-2} \cdot \mathrm{s}^{-1}$ e $33^{\circ} \mathrm{C}$ (luz natural). Após 60 dias, avaliaram-se comprimento de parte aérea, massa fresca e seca de parte aérea e raízes, espessuras dos tecidos do limbo foliar, além de número, diâmetro polar e equatorial dos estômatos. O experimento foi instalado em delineamento inteiramente casualizado. Os resultados mostraram-se significativos para interação entre suportes físicos e ambientes para todas as variáveis analisadas. O uso do substrato vermiculita em luz artificial apresentou melhores resultados para todas as variáveis, exceto para número de estômatos. Para as características anatômicas, maiores espessuras dos tecidos do limbo foliar foram verificadas quando se utilizaram vermiculita e luz natural, sendo que, para o uso de ágar, também houve aumento das espessuras somente quando se utilizou o ambiente de luz natural. Quanto ao número de estômatos $/ \mathrm{mm}^{2}$, não houve diferença significativa para os tratamentos. Maior diâmetro polar e equatorial foi observado em estômatos de folhas cultivadas em luz artificial e vermiculita, e luz natural e vermiculita, respectivamente.

Termos para indexação: Ananas comosus, ambiente de cultivo e anatomia vegetal.

\section{MORPHOPHYSIOLOGICAL CHARACTERISTICS OF PINEAPPLE 'GOMO DE MEL' ROOTED IN VITRO UNDER NATURAL LIGHT AND VERMICULITE SUBSTRATE}

\begin{abstract}
This study aimed to evaluate the effect of vermiculite, agar, artificial light and natural light in the in vitro rooting of pineapple shoots 'Gomo de Mel' propagules, as well as, to characterize these plants anatomically. The study was performed at the Plant Tissue Culture Laboratory of the Department of Agriculture - UFLA, Lavras-MG. It was used shoots with $2 \mathrm{~cm}$ of length cultivated in MS medium added with $30 \mathrm{~g} . \mathrm{L}^{-1}$ of sucrose. Two physical supports were tested: $6 \mathrm{~g} . \mathrm{L}^{-1}$ of agar and $15 \mathrm{~g} . \mathrm{L}^{-1}$ of vermiculite for the shoot rooting in two environments: growth room $25 \pm 1{ }^{\circ} \mathrm{C}, 45 \mathrm{~W} \cdot \mathrm{m}^{-2} \cdot \mathrm{s}^{-1}$ during 16 hours and greenhouse with radiation of $115,08 \mathrm{~W} \cdot \mathrm{m}^{-2} \cdot \mathrm{s}^{-1}$ and $33^{\circ} \mathrm{C}$ (natural light). After 60 days, it was evaluated the aerial part length, fresh and dry mass of aerial part and roots, the thicknesses of foliar limb tissues, besides the number, polar and equatorial diameter of the stomata. The experiment was installed in a completely randomized design. The results showed significance in the interaction between physical supports and environment for all analyzed variables. The use of the vermiculite substrate in artificial light presented better results in all variables, except for number of stomata. For the anatomical characteristics, bigger thicknesses of the foliar limb tissues was verified when it was used vermiculite and natural light, being that, for the agar use, it also increased the thicknesses only when the environment of natural light was used. Regarding the number of stomata $/ \mathrm{mm}^{2}$, did not have significant difference between treatments. A greater polar and equatorial diameter was observed in stomata of leaves cultivated in artificial light and vermiculite and natural light and vermiculite respectively. Index terms: Ananas comosus, growing environment and vegetal anatomy.
\end{abstract}

\footnotetext{
1(Trabalho 131-10). Recebido em: 24-05-2010. Aceito para publicação em: 03-09-2010.

${ }^{2}$ Prof. Adjunta da Universidade do Estado da Bahia (UNEB), Campus VIII, CEP: 48608-240, Paulo Afonso-BA. E-mail: ftbraga@yahoo.com.br. ${ }^{3}$ Prof. Titular da Universidade Federal de Lavras (UFLA), Departamento de Agricultura, Caixa Postal 37, CEP $37200-000$ Lavras-MG. E-mail: mpasqual@ufla.br.

${ }^{4}$ Prof. Adjunto da UFLA, Departamento de Biologia. Caixa Postal 37, CEP 37200-000 Lavras-MG. Email: emcastro@ufla.br. ${ }^{5}$ Graduando em Engenharia Florestal da Universidade Federal de Lavras (UFLA), Departamento de Agricultura, Caixa Postal 37, CEP 37200-000 Lavras-MG. E-mail: gcoimbra_ufla@yahoo.com.br
} 


\section{INTRODUÇÃO}

Uma das principais limitações à expansão do uso da micropropagação de abacaxizeiro é o elevado custo das mudas, cujo gasto com energia elétrica em salas de crescimento é um dos fatores mais onerosos.

Uma alternativa para esse fator seria o cultivo in vitro em ambiente de luz natural. Essa tecnologia não é muito adotada por não estarem esclarecidos seus efeitos sobre as culturas que, convencionalmente, são condicionadas em luz artificial, com intensidades luminosas inferiores e com fotoperíodo e temperatura controlada (ERIG; SCHUCH, 2005).

No método convencional de micropropagação, a etapa de enraizamento in vitro é realizada em meio nutritivo contendo ágar, porém o sistema radicular emitido em meio com esse suporte é, em geral, pouco ramificado, quebradiço e com poucos pelos radiculares (HOFFMANN et al., 2001), o que reduz a capacidade de absorção de água e nutrientes durante o processo de aclimatização. O ágar também é considerado um dos componentes que elevam o custo de produção no cultivo in vitro (APTER et al., 1993; LEITE et al., 2002).

Diversos trabalhos citam o uso de suportes alternativos para enraizamento de brotos em sistemas intensivos de micropropagação (MARTINÉZ-HERNÁNDEZ et al., 2006; LEITE et al., 2002; HOFFMANN et al., 2001). Esses autores citam vermiculita, perlita ou espumas de poliuretano embebidos com meio líquido como alternativas de baixo custo, além de conferirem melhores resultados que o ágar.

Assim, o presente trabalho teve como objetivo avaliar o efeito da vermiculita, ágar, luz artificial e natural no enraizamento in vitro de brotos de abacaxizeiro 'Gomo de Mel', bem como caracterizar anatomicamente essas plantas.

\section{MATERIAL E MÉTODOS}

O trabalho foi conduzido no Laboratório de Cultura de Tecidos Vegetais do Departamento de Agricultura da Universidade Federal de Lavras, localizado na cidade Lavras-MG, durante o período de agosto a novembro de 2008 .

O material vegetal utilizado de abacaxi já se encontrava estabelecido in vitro, o mesmo foi subcultivado em meio MS (MURASHIGE; SKOOG, 1962) líquido, suplementado com adição de $30 \mathrm{~g} \mathrm{~L}^{-1}$ de sacarose para posterior utilização no experimento.

Para o enraizamento in vitro dos brotos, foram utilizados como suportes físicos: 1) ágar 6 g. $\mathrm{L}^{-1}$, e 2) vermiculita 15 g. $\mathrm{L}^{-1}$, adicionados ao meio de cultura MS líquido para o tratamento vermiculita e sólido para o ágar, acrescido de 30 g. $\mathrm{L}^{-1}$ de sacarose, com $\mathrm{pH}$ ajustado para 5,8 antes da autoclavagem a $121^{\circ} \mathrm{C}$ e $1,2 \mathrm{~atm}$, durante 20 minutos. .

Os frascos com capacidade para $200 \mathrm{~mL}^{-1}$ foram fechados com tampas de polipropileno e vedados com parafilme. As culturas foram mantidas em duas condições ambientais: 1) sala de crescimento (luz artificial) a $25 \pm 2^{\circ} \mathrm{C}$, irradiância de $45 \mathrm{~W} . \mathrm{m}^{-2}$ fornecida por lâmpadas fluorescentes brancas de $20 \mathrm{~W}$ e fotoperíodo de 16 horas, e 2) casa de vegetação (luz natural). A radiação e a temperatura dentro da casa de vegetação foram avaliadas utilizando sensor de radiação (LI-200SA, Li-cor, Lincoln, Nevasca, USA), acoplados a um sistema de registro (LI 1400; Li-cor.Neb), a cada meia hora, durante 12 horas (das 06 às 18 horas). Os dados da caracterização do comportamento diurno da radiação solar e da temperatura estão apresentados na Figura 1 A e B.

Decorridos 60 dias da instalação do experimento, avaliaram-se o comprimento da parte aérea, as massas fresca e seca da parte aérea e as raízes.

As características anatômicas das folhas cultivadas in vitro foram avaliadas seguindo o protocolo de Kraus e Arduin (1997), registrando-se: espessura das epidermes adaxial e abaxial, parênquimas aquífero e clorofiliano. As variáveis paradérmicas, número de estômatos $/ \mathrm{mm}^{2}$ e diâmetros polar e equatorial, foram caracterizadas segundo técnica de Laboriau et al. (1961).

O experimento foi instalado em delineamento inteiramente casualizado, em esquema fatorial $2 \times 2$, com quatro tratamentos e dez repetições, cada uma composta por um frasco contendo cinco brotos. Os dados foram submetidos à análise de variância, onde as médias foram comparadas pelo teste de Tukey, a $5 \%$ de probabilidade. As análises estatísticas foram realizadas utilizando o software Sisvar 5.0 (FERREIRA, 2000).

\section{RESULTADOS E DISCUSSÃO}

Os resultados mostraram efeito significativo dos tratamentos para todas as variáveis analisadas e para a interação dos suportes físicos e condições ambientais. O uso de vermiculita em luz artificial (sala de crescimento convencional) apresentou melhores resultados para todas as variáveis (Tabela 1).

Não foram observadas contaminações bacterianas e fúngicas em nenhum dos tratamentos estudados, mesmo aqueles incubados sob condições de luz natural.

Mesmo o ambiente de luz artificial, proporcionando maior comprimento de parte aérea, plantas oriundas do enraizamento em luz natural (casa de 
vegetação) apresentaram folhas mais espessas (Tabela 2), o que sugere uma adaptação ao ambiente de maior irradiância. Brotos enraizados em condições de luz artificial sofreram processo de estiolamento, devido à baixa irradiância da sala de crescimento, o que favoreceu maior comprimento e, consequentemente, maior massa fresca da parte aérea.

Plantas enraizadas em meio contendo vermiculita e luz artificial apresentaram raízes com mais ramificações e presença de pelos absorventes, o que pode contribuir para o processo de aclimatização, por possibilitar maior área de contato das raízes com o substrato, facilitando a absorção de água e nutrientes (Tabela 1).

Da mesma forma, Faria et al. (2006) avaliaram o uso de ágar, espuma picada, esfagno e areia grossa na propagação in vitro de orquídea (Oncidium baueri) e observaram que espuma picada apresentou melhores resultados para todas as variáveis estudadas.

O uso de suportes físicos alternativos ao ágar é relatado por vários autores. Corroborando os resultados apresentados neste trabalho Martínez-Hernández et al. (2006), trabalhando com duas cultivares de Citrus tolerantes ao vírus da tristeza, observaram que, para germinação, multiplicação e enraizamento in vitro, o uso de substratos alternativos (vermiculita, tezontle e agrolita) não apresentaram diferenças significativas, o que permitiu comprovar que a substituição ao ágar é viável, podendo utilizar substratos inertes nas etapas da micropropagação.

Os resultados apresentados neste trabalho discordam daqueles apresentados por Hoffmann et al. (2001), que avaliaram três substratos: ágar, Plantmax ${ }^{\circledR}$ + ágar e vermiculita + ágar, em dois porta-enxertos de macieira. Os autores observaram que, tanto para indução de enraizamento, quanto para o desenvolvimento das raízes adventícias, o uso apenas de ágar apresentou maiores taxas de enraizamento.

Quanto ao ambiente de luz, resultados semelhantes aos obtidos neste trabalho foram observados por Silva et al. (2008), que avaliaram o uso da luz natural no enraizamento in vitro e aclimatização do abacaxi cv. Imperial e observaram que a luz artificial promoveu maior comprimento de raízes em relação à luz natural. Os resultados apresentados podem estar relacionados com a função das auxinas no enraizamento. Este grupo de fitormônios é fotodegradado, e o aumento da radiação no ambiente de casa de vegetação pode reduzir sua concentração endógena e promover menor crescimento e desenvolvimento dessas raízes.

As secções transversais das folhas oriundas do enraizamento in vitro, utilizando vermiculita e ágar como suporte e luz natural e artificial como fonte de irradiação, apresentaram somente uma camada de epiderme em ambas as faces abaxial e adaxial, sendo, portanto, unisseriadas. A presença de estômatos foi verificada apenas na face abaxial da epiderme (hipoestomáticas), presença de dois tipos de tricomas: glandulares e escamiformes, parênquima aquífero espesso e bem desenvolvido, parênquima clorofiliano com células arredondadas, apontando a presença de amido em seu interior e fibras ao longo desse tecido (Figura 2).

$\mathrm{O}$ uso da luz natural como ambiente de incubação promoveu maior deposição de cera epicuticular nas epidermes das folhas (Figura 2 D). Sabe-se que as principais funções da cutícula são a proteção contra a perda de água e a proteção contra o excesso de luminosidade por se tratar de uma camada brilhante e refletora. A permeabilidade da água através da cutícula é influenciada principalmente pela estrutura e quantidade de ceras epicuticulares. Pouca deposição de cera epicuticular sobre a superfície das folhas das plantas cultivadas in vitro também tem sido considerada como um fator responsável pela perda excessiva de água, levando ao insucesso no processo de aclimatização (HAZARIKA, 2006).

Observaram-se diferenças significativas para todas as variáveis analisadas, exceto para espessura da epiderme abaxial (Tabela 2). Maiores espessuras dos tecidos do mesófilo foliar foram verificadas quando se utilizaram vermiculita e luz natural, sendo que, para o uso de ágar, houve também aumento das espessuras somente no ambiente de luz natural, demonstrando a adaptação dos tecidos às condições de alta irradiância.

$\mathrm{O}$ aumento na espessura dos tecidos que compõem o limbo constitui um padrão clássico de resposta e de adaptação das plantas à alta intensidade de luz e evidenciam a plasticidade adaptativa da planta (LEE et al., 2000). A capacidade de alterar a estrutura da folha em resposta ao ambiente, principalmente ao nível de irradiância, tem sido comumente observada em diversas espécies (kiwi, banana e abacaxi), cultivadas in vitro (DIMASSITHERIOU; BOSABALIDIS, 1997; ROCHA, 2007; SILVA et al., 2008).

Quanto às características paradérmicas, houve interação significativa entre os fatores suporte físico e ambiente de cultivo apenas para diâmetro polar e razão diâmetro polar e equatorial, e os resultados não foram significativos para número de estômatos. Para variável diâmetro equatorial, houve diferenças significativas apenas para os fatores isoladamente (Tabela 3).

Para número de estômatos $/ \mathrm{mm}^{2}$, luz natural como ambiente de cultivo e ágar como suporte apre- 
sentaram a maior média. Maior diâmetro polar foi observado em estômatos provenientes de ambiente de luz artificial e vermiculita. Maior diâmetro equatorial foi obtido em ambiente de luz natural e suporte vermiculita, separadamente. Maior razão diâmetro polar/equatorial foi verificada em luz artificial e ágar.

Alguns autores descrevem que, apesar de a variabilidade estomática ser um fenômeno relacio- nado principalmente à umidade relativa dentro dos frascos, a intensidade luminosa pode ter implicações nesse processo (DIGNART et al., 2009; BRAGA et al., 2009). Assim, de acordo com os resultados apresentados, pode-se notar que as maiores densidades estomáticas estão geralmente associadas à alta irradiância.

TABELA 1- Massa fresca de parte aérea (MFA), massa fresca de raízes (MFR), massa seca de parte aérea (MSA), massa seca de raízes (MSR) e comprimento de parte aérea (CPA), de abacaxizeiro enraizado in vitro sob condições de luz natural e suporte convencional. Lavras-MG.

\begin{tabular}{|c|c|c|c|c|}
\hline & \multicolumn{2}{|c|}{ MFA $\left(\mathrm{g}^{-1}\right)$} & \multicolumn{2}{|c|}{$\operatorname{MFR}\left(\mathrm{g}^{-1}\right)$} \\
\hline & Vermiculita & Ágar & Vermiculita & Ágar \\
\hline Luz Artificial & $3,63 \mathrm{aA}$ & $2,01 \mathrm{bA}$ & $0,55 \mathrm{aA}$ & $0,18 \mathrm{bB}$ \\
\hline \multirow[t]{3}{*}{ Luz Natural } & $1,49 \mathrm{aB}$ & $2,16 \mathrm{aA}$ & $0,09 \mathrm{bB}$ & $0,37 \mathrm{aA}$ \\
\hline & \multicolumn{2}{|c|}{$\operatorname{MSA}\left(\mathrm{g}^{-1}\right)$} & \multicolumn{2}{|c|}{$\operatorname{MSR}\left(\mathrm{g}^{-1}\right)$} \\
\hline & Vermiculita & Ágar & Vermiculita & Ágar \\
\hline Luz Artificial & $0,21 \mathrm{aA}$ & $0,14 \mathrm{bA}$ & $0,044 \mathrm{aA}$ & $0,015 \mathrm{bB}$ \\
\hline \multirow[t]{3}{*}{ Luz Natural } & $0,12 \mathrm{bB}$ & $0,19 \mathrm{aA}$ & $0,007 \mathrm{bB}$ & $0,025 \mathrm{aA}$ \\
\hline & \multicolumn{4}{|c|}{ CPA (cm) } \\
\hline & \multicolumn{2}{|c|}{ Vermiculita } & \multicolumn{2}{|c|}{ Ágar } \\
\hline Luz Artificial & \multicolumn{2}{|c|}{$14,9 \mathrm{aA}$} & \multicolumn{2}{|c|}{$10,34 \mathrm{bA}$} \\
\hline Luz Natural & \multicolumn{2}{|c|}{$5,05 \mathrm{bA}$} & \multicolumn{2}{|c|}{$8,49 \mathrm{aB}$} \\
\hline
\end{tabular}

*Médias seguidas da mesma letra minúscula na linha e maiúscula na coluna não diferem entre si, pelo teste de Tukey, a 5\% de probabilidade.

TABELA 2 - Espessura dos tecidos do limbo foliar ${ }^{(1)}$ de abacaxizeiro enraizados in vitro sob condições de luz natural e suporte convencional. Lavras-MG

\begin{tabular}{|c|c|c|}
\hline & \multicolumn{2}{|c|}{ Epiderme Abaxial $(\mu \mathrm{m})$} \\
\hline Luz Artificial & \multicolumn{2}{|c|}{$20,21 \mathrm{a}$} \\
\hline Luz Natural & \multicolumn{2}{|c|}{$19,20 \mathrm{a}$} \\
\hline Vermiculita & \multicolumn{2}{|c|}{$21,10 \mathrm{a}$} \\
\hline \multirow[t]{3}{*}{ Ágar } & \multicolumn{2}{|c|}{$18,88 \mathrm{a}$} \\
\hline & \multicolumn{2}{|c|}{ Parênquima Clorofiliano $(\mu \mathrm{m})$} \\
\hline & Vermiculita & Ágar \\
\hline Luz Artificial & $177,15 \mathrm{aB}$ & $162,68 \mathrm{bA}$ \\
\hline \multirow[t]{3}{*}{ Luz Natural } & $358,87 \mathrm{aA}$ & $167,06 \mathrm{bA}$ \\
\hline & \multicolumn{2}{|c|}{ Parênquima Aquifero ( $\mu \mathrm{m})$} \\
\hline & Vermiculita & Ágar \\
\hline Luz Artificial & $186,01 \mathrm{aB}$ & $137,65 \mathrm{bA}$ \\
\hline \multirow[t]{3}{*}{ Luz Natural } & $257,99 \mathrm{aA}$ & $128,30 \mathrm{bA}$ \\
\hline & \multicolumn{2}{|c|}{ Epiderme Abaxial $(\mu \mathrm{m})$} \\
\hline & Vermiculita & Ágar \\
\hline Luz Artificial & $20,83 \mathrm{aB}$ & $18,78 \mathrm{aA}$ \\
\hline Luz Natural & $27,41 \mathrm{aA}$ & $19,27 \mathrm{bA}$ \\
\hline
\end{tabular}

"Médias seguidas da mesma letra minúscula na linha e maiúscula na coluna não diferem entre si, pelo teste de Tukey, a 5\% de probabilidade. 
TABELA 3 - Número de estômatos (NE), diâmetro polar (DP) e equatorial (DE) e razão diâmetro polar e equatorial (DP/DE) de estômatos de abacaxizeiro enraizados in vitro sob condições de luz natural e suporte convencional. Lavras-MG.

\begin{tabular}{|c|c|c|c|c|}
\hline \multirow{4}{*}{$\begin{array}{l}\text { Luz Artificial } \\
\text { Luz Natural }\end{array}$} & \multicolumn{4}{|c|}{$\mathrm{NE}\left(\mathrm{mm}^{2}\right)$} \\
\hline & \multicolumn{2}{|c|}{ Vermiculita } & \multicolumn{2}{|c|}{ Ágar } \\
\hline & \multicolumn{2}{|c|}{43,50 aA } & \multicolumn{2}{|c|}{$36,95 \mathrm{aA}$} \\
\hline & \multicolumn{2}{|c|}{$36,95 \mathrm{aA}$} & \multicolumn{2}{|c|}{$45,51 \mathrm{aA}$} \\
\hline & \multicolumn{2}{|c|}{ Razão DP/DE $(\mu \mathrm{m})$} & \multicolumn{2}{|c|}{ Diâmetro Polar $(\mu \mathrm{m})$} \\
\hline & Vermiculita & Ágar & Vermiculita & Ágar \\
\hline Luz Artificial & $1,003 \mathrm{aA}$ & $1,062 \mathrm{aA}$ & $36,41 \mathrm{aA}$ & $32,02 \mathrm{bB}$ \\
\hline \multirow[t]{2}{*}{ Luz Natural } & $0,792 \mathrm{bB}$ & $1,007 \mathrm{aA}$ & $30,79 \mathrm{bB}$ & $35,58 \mathrm{aA}$ \\
\hline & \multicolumn{4}{|c|}{ Diâmetro Equatorial $(\mu \mathrm{m})$} \\
\hline Luz Artificial & \multirow{2}{*}{\multicolumn{4}{|c|}{$\begin{array}{l}33,47 \mathrm{~b} \\
37,30 \mathrm{a}\end{array}$}} \\
\hline Luz Natural & & & & \\
\hline Vermiculita & \multicolumn{4}{|c|}{$37,84 \mathrm{a}$} \\
\hline Ágar & \multicolumn{4}{|c|}{$33,14 \mathrm{~b}$} \\
\hline
\end{tabular}

"Médias seguidas da mesma letra minúscula na linha e maiúscula na coluna não diferem entre si, pelo teste de Tukey, a 5\% de probabilidade.

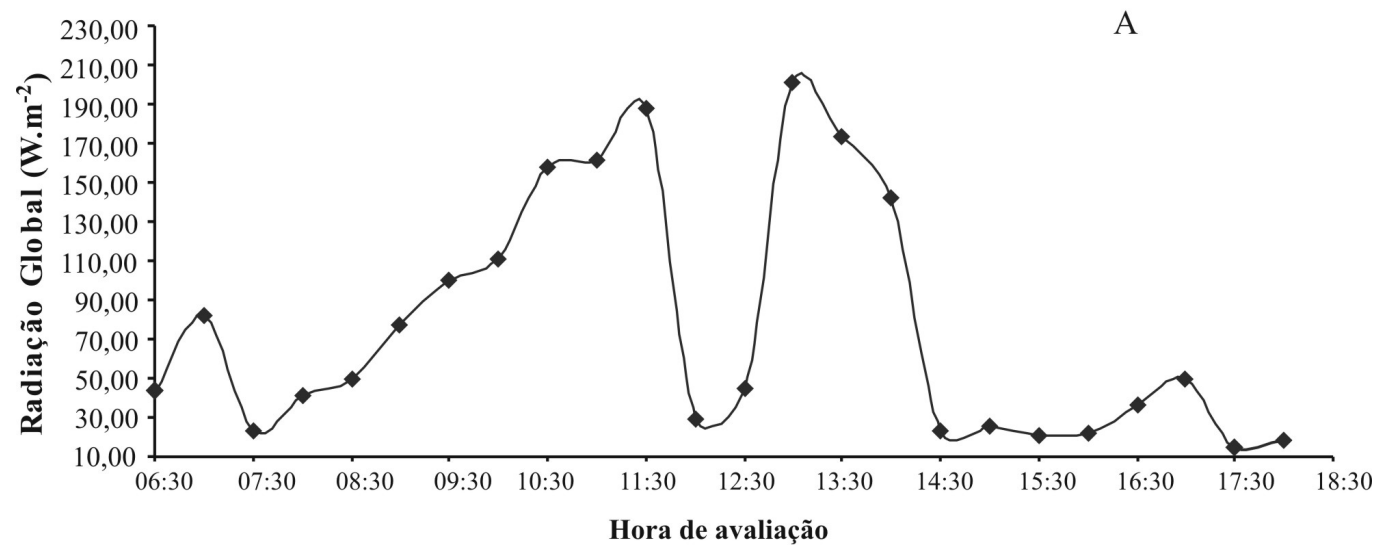

B

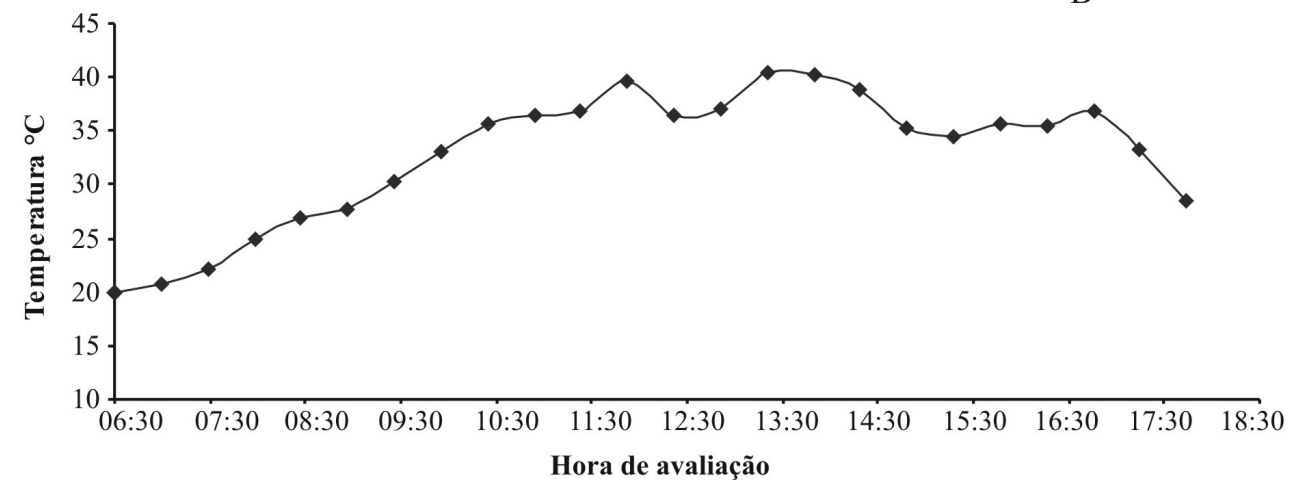

FIGURA 1 - Comportamento diurno da radiação solar (A) e temperatura (B) na casa de vegetação (luz natural). Lavras-MG (2008). 


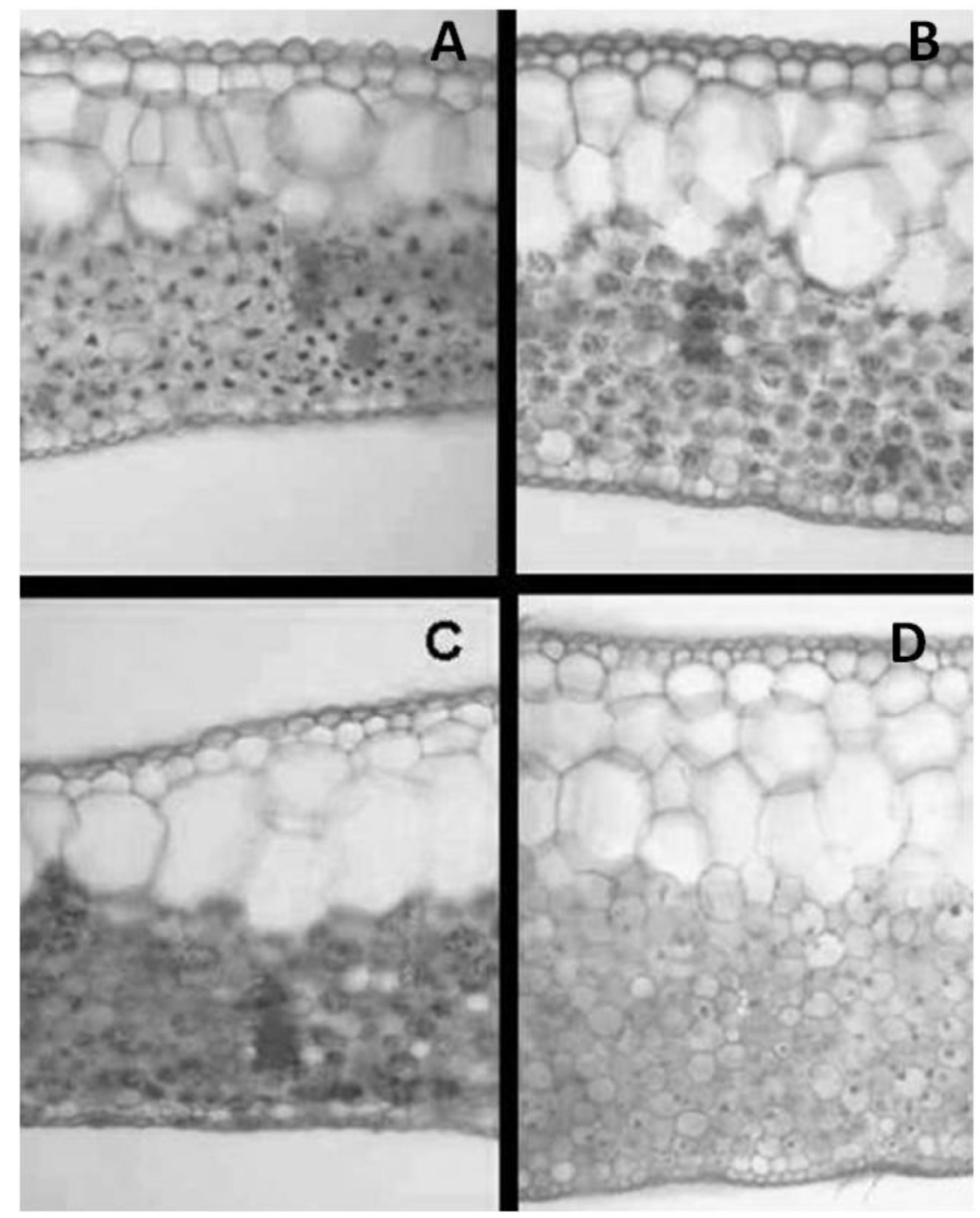

FIGURA 2 - Fotomicrografias de secções transversais de folhas de abacaxizeiro enraizadas in vitro com diferentes substratos e luz natural. (A) ágar e luz artificial; (B) ágar e luz natural; (C) vermiculita e luz artificial, e (D) vermiculita e luz natural. Lavras-MG (2008).

\section{CONCLUSÕES}

1-A vermiculita, como suporte físico alternativo ao ágar e ambiente de luz artificial (sala de crescimento), promove maior crescimento in vitro de brotos de abacaxizeiro.

2-Luz natural (casa de vegetação) proporciona maiores espessuras dos tecidos do limbo foliar.

3-Maior número de estômatos é obtido em folhas desenvolvidas em ambiente de luz natural e suporte ágar.

\section{AGRADECIMENTOS}

À Fundação de Amparo à Pesquisa do Estado de Minas Gerais, ao Conselho Nacional de Desenvolvimento Científico e Tecnológico e à Coordenação de Aperfeiçoamento de Pessoal de Nível Superior, pelo apoio financeiro recebido. 


\section{REFERÊNCIAS}

APTER, R.C.; MCWILLIAMS, E.L.; DAVIES JÚNIOR, F.T. In vitro and ex vitro adventitious root formation in Asian jasmine (Trachelospermum asiaticum): I, comparative morphology. Journal of the American Society for Horticultural Science, Alexandria, v.118, n. 6, p. 902-905, 1993.

BRAGA, F.T.; PASQUAL, M.; CASTRO, E.M. de; DIGNART, S.L.; BIAGIOTTI, G.; PORTO, J.M.P. Qualidade de luz no cultivo in vitro de Dendranthema grandiflorum cv. rage: características morfofisiológicas. Ciência e Agrotecnologia, Lavras, v. 33, n. 2, p. 502-508, 2009.

DIGNART, S.L.; CASTRO, E.M. de; PASQUAL, M.; FERRONATO, A.; BRAGA, F.T.; PAIVA, R. Luz natural e concentrações de sacarose no cultivo in vitro de Cattleya walkeriana. Ciência e Agrotecnologia, Lavras, v. 33, n. 3, p. 780-787, 2009.

DIMASSI-THERIOU, K.; BOSABALIDIS, A.M. Effects of light, magnesium and sucrose on leaf anatomy, photosynthesis, starch and total sugar accumulation, in Kiwifruit cultured in vitro. Plant Cell, Tissue and Organ Culture, Dordrecht, v.47, n.2, p.127-134, 1997.

ERIG, A.C.; SCHUCH, M.W. Micropropagação fotoautotrófica e uso da luz natural. Revista Ciência Rural, Santa Maria, v.35, n.4, p.961-965, jul/ ago. 2005.

FARIA, R.T.; DALIO, R.J.D.; UNEMOTO, L.K.; SILVA, G.L. Propagação in vitro de Oncidium baueri Lindl. (Orchidaceae) sem uso de ágar. Revista Acta Scientific Agronomy, Maringá, v. 28, n. 1, p. 7174, 2006.

FERREIRA, D.F. Sisvar 5.0: sistema de análise estatística. Lavras: UFLA/DEX, 2000. Software.

HAZARIKA, B.N. Morpho-physiological disorders in in vitro culture of plants. Scientia Horticulturae, Amsterdam, v.108, n.1, p.105-120, 2006.

HOFFMANN, A.; PASQUAL, M.; CHALFUN, N.N.J.; VIEIRA, S.S.N. Substratos na indução e desenvolvimento in vitro de raízes em dois portaenxertos de macieira. Pesquisa Agropecuária Brasileira, Brasília, v.36, n.11, p.1371-1379, 2001.
KRAUS, J.E.; ARDUIM, M. Manual básico de métodos em morfologia vegetal. Rio de Janeiro: Seropédica, 1997. 198p.

LABORIAU, L.G.; OLIVEIRA, J.G.; SALGADOLABORIAU, M.I. Transpiração de Schizolobium parahyba (vell) Toledo: I, comportamento na estação chuvosa, nas condições de Caeté, Minas Gerais. Anais da Academia Brasileira de Ciências, Rio de Janeiro, v.33, n.2, p.237-252, 1961.

LEE, D.W.; OBERBAUER, S.F.; JOHNSON, P.; KRISHNAPILAY, B.; MANSOR, M.; MOHAMAD, H.; YAP, S.K. Effects of irradiance and spectral quality on leaf structure and function in seedlings of two southeast asian Hopea (Dipeterocarpaceae) species. American Journal of Botany, Columbus, v.87, n.4, p.447-455, 2000.

LEITE, G.B.; FINARDI, N.L.; FORTES, G.R.L. Use of vermiculite as a substrate and effect of light on in vitro rooting of pears, cv. Bartlett and clone oh x f97. Ciência e Agrotecnologia, Lavras, v.26, n.5, p.977-982, set./out. 2002.

MARTÍNEZ-HERNÁNDEZ, M.J.; LÓPEZ, A.A.; OSORIO-ACOSTA, F.; LÓPEZ, F.G.; MOCTEZUMA, H.L.; ROSAS, M.M. Cultivo in vitro de patrones de cítricos tolerantes al virus de la tristeza, empleando sustratos inertes alternativos al ágar. Interciência, Caracas, v.31, n.8, p.616-619, 2006.

MURASHIGE, T.; SKOOG, F. A revised médium for rapid growth and bioassays with tobacco tissue cultures. Physiologia Plantarum, Copenhagem, v.15, n.3, p.473-497, 1962.

ROCHA, H.S.; SILVA, C.R.R.; ARAÚJO, A.G.; SILVA, A.B. Propagação in vitro de bananeira 'Prata-anã (AAB)': intensidades luminosas e concentrações de sacarose nas fases de multiplicação e enraizamento. Plant Cell Culture and Micropropagation, Lavras, v.3, n.1, p. 10-17, 2007.

SILVA, A.B. da; PASQUAL, M.; CASTRO, E.M. de; MIYATA, L.Y.; MELO, L.A. de; BRAGA, F.T. Luz natural na micropropagação do abacaxizeiro (Ananas comosus L. Merr). Interciencia, Caracas, v. 33, n. 11, p.839-843, 2008. 